\title{
Cinema e Vídeo em Escolas da Rede Pública de São Paulo: Experiência de Ensino e Aprendizagem
}

\author{
Cinema and Video in Public Schools of São Paulo: \\ Experience of Teaching and Learning
}

\section{RESUMO}

Este artigo analisa a experiência de oficinas audiovisuais desenvolvidas no interior do Programa Novos Talentos da Pró-Reitoria de Cultura e Extensão Universitária da USP, coordenado pela professora Vera Baeta Henriques e financiado pela Capes (Coordenação de Aperfeiçoamento de Pessoal de Nível Superior). Neste ano, o projeto está completando dois anos de atividades. Dentre suas realizações, encontram-se as atividades de oficinas de vídeo em escolas da rede pública de ensino de São Paulo, executadas por membros - estagiários e oficineiros - associados ao CINUSP Paulo Emílio (Cinema da Universidade de São Paulo). O presente artigo pretende trazer uma abordagem reflexiva e crítica sobre o percurso das oficinas nas escolas, apontando quais foram seus primeiros objetivos e métodos, assim como seus primeiros resultados e debates. Também descreve quais mudanças foram necessárias realizar no percurso das oficinas e quais ideias surgiram do contato com os alunos e as instituições escolares.

Palavras-chave: Oficinas de Vídeo. Educação. Cinema.

\begin{abstract}
The Culture and Extension Project of USP, Novos Talentos, which is sponsored by Capes, has been developed now for two years. Among its accomplishments, there are activities such as the video workshops that take place at Public Schools from the State of São Paulo, leaded by associate members - trainees and educators - of the CINUSP Paulo Emílio. This paper aims to share a reflective and critical approach concerning this work's pathway, pointing to its first objectives and methods, as well as to its first results and discussions. There are also described some changes that have become necessary in order to develop the video workshops and some of the outcomes brought by the contact with the students and their schools.
\end{abstract}

Keywords: Video Workshops. Education. Cinema.

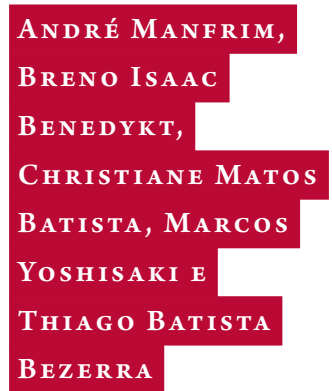

Universidade de São Paulo. CINUSP Paulo Emílio, São Paulo, Brasil 


\section{INTRODUÇÃO}

Desde 2011, o CINUSP Paulo Emílio, no interior do tripé universitário de Cultura e Extensão, promove oficinas de vídeo engajadas na inserção da cultura audiovisual na educação pública da região metropolitana de São Paulo. O trabalho faz parte do projeto interdisciplinar Novos Talentos, financiado pela Capes e encabeçado pela Comissão de Cultura e Extensão do Instituto de Física da Universidade de São Paulo (IF-USP). O componente audiovisual do projeto é coordenado pelo CINUSP em parceria com a Faculdade de Educação (FE-USP) e a Escola de Comunicações e Artes (ECA-USP). Enquanto outros componentes do projeto estão voltados diretamente ao desenvolvimento de atividades curriculares, as oficinas de vídeo - seja com professores, seja com alunos, ou com ambos - são inseridas no contexto escolar como atividades extracurriculares e, como tais, suscitam questões específicas: (1) disponibilidade de professores e alunos para o estabelecimento de compromissos no contraturno escolar e (2) viabilidade da disponibilização, por parte da escola, de sua infraestrutura no período das oficinas.

Em janeiro de 2011, professores, técnicos, estagiários e oficineiros ligados ao CINUSP realizaram oficinas para professores no âmbito do Encontro USP-Escola; no segundo semestre do mesmo ano e ao longo de 2012 e 2013, foram realizadas oficinas de vídeo para alunos da rede pública de ensino de São Paulo que aconteceram nas sedes das suas escolas. Este artigo analisa a experiência das oficinas nas escolas com alunos do ensino fundamental e ensino médio, realizadas por estagiários e oficineiros.

Um breve mapeamento histórico de documentos oficiais que regulam a educação brasileira sugere que o trabalho com conteúdos e técnicas audiovisuais em escolas passou a ser estimulado a partir das exigências incluídas nos Parâmetros Curriculares Nacionais de 2000, que valorizam atividades educativas extraescolares. Essas exigências foram incluídas nas Diretrizes Curriculares do Estado de São Paulo no ano de 2008, produzindo novas aberturas para iniciativas como a aqui apresentada, uma vez que preveem, entre outras coisas, o incentivo à realização de atividades educacionais extracurriculares, ou seja, atividades inovadoras, que estejam fora das propostas estritamente previstas para o ensino das disciplinas regulares em sala de aula. As oficinas de vídeo são atividades extracurriculares e interdisciplinares que entendem o trabalho com vídeo como um facilitador no processo ensino-aprendizagem que, além de permitir o diálogo entre diversas áreas do conhecimento, estimula os alunos a exercitar sua criatividade a partir do uso de uma linguagem já incorporada ao cotidiano, porém cujos processos de produção são menos evidentes e intuitivos do que parecem ser.

As oficinas de vídeo realizadas nas escolas são conduzidas por alunos de graduação e recém-formados nas áreas de comunicação, artes e educação. Assim, o trabalho pôde promover o encontro entre dois aparelhos públicos de ensino: um seletivo, a Universidade de São Paulo, e outro obrigatório, representado por três instituições de ensino público: Escola Municipal Jardim da Conquista, em Perus, Escola Estadual Professor Gabriel Ortiz, na Penha e Escola Estadual Augusto de Oliveira Jordão, no município de Diadema. O trabalho nas escolas nasceu a partir da repercussão que teve uma oficina realizada com professores durante o Encontro USP-Escola no ano 
de 2011, quando foi solicitado por alguns dos docentes participantes que o trabalho fosse também desenvolvido nas escolas, junto aos seus alunos.

\section{OBJETIVOS E METODOLOGIA}

Os objetivos das oficinas são: sensibilizar e capacitar os alunos a manipular os códigos e técnicas da realização audiovisual e propiciar o reposicionamento dos alunos em sua escola e bairro de moradia a partir da expressão audiovisual. Os desafios do projeto envolvem a definição de estratégias para que os objetivos das oficinas fossem realizáveis a partir do contexto social dos alunos, das estruturas físicas e institucionais das escolas e do próprio projeto. Vale observar a relação de estranhamento que em geral cerca escolas - avessas ao universo das tecnologias digitais, no qual os alunos transitam muito bem - e os meios audiovisuais, especialmente o cinema, a TV e a internet. Observamos que a desigualdade social brasileira se expressa e se reproduz na centralização dos meios de produção e distribuição audiovisual. Conteúdos audiovisuais, com raras exceções, reforçam discriminações de gênero, cor e classe social. Oficinas de audiovisual com alunos e professores de escolas públicas podem contribuir para gerar parâmetros estéticos e políticos capazes de desarticular discriminações. Vistas dessa perspectiva, essas oficinas ajudam também a reposicionar escolas dispostas a desenvolver seu potencial de produção de conhecimento.

A inspiração teórica para o trabalho se adensou em contato com a Profa. Dra. Moira Toledo*, cuja experiência em ensino de audiovisual com jovens de baixa renda é extensa, de grande reconhecimento e importância. Deste encontro foram retiradas reflexões importantes que auxiliariam na elaboração de estratégias de como obter um contato mais efetivo com os alunos, além de auxiliar na elaboração de uma metodologia. Sua tese de doutorado na ECA [4] serviu de base teórica para as oficinas, visto que a sua pesquisa mapeou quase a totalidade das experiências com educação audiovisual popular no Brasil no período entre 1990 e 2009. Após extenso levantamento quantitativo, Toledo fundamenta os princípios pedagógicos e filosóficos dos processos formativos desencadeados nos alunos. $\mathrm{O}$ centro propulsor da análise de Toledo é Paulo Freire - onipresente no discurso de coordenadores, professores e pesquisadores do EAP - e sua pedagogia da autonomia.

Pensamos, então, numa metodologia e, por meio dela, no desenvolvimento de estratégias que levassem em conta a desconstrução dos discursos que restringem a experiência do processo de criação audiovisual, visto que existe em nossa sociedade uma série de discursos que paralisam as vontades de criar através da prerrogativa de que o

\footnotetext{
*A descrição de seu percurso profissional é bastante longa, mas, para a presente escrita, é importante dizer que Moira Toledo atuou como educadora e colaboradora pedagógica em projetos como o Perifa, as Oficinas Kinoforum, as Oficinas do Festival do Minuto, a Casa do Zezinho e a Academia Internacional de Cinema. Ver: Toledo, M. (2010). Educação Audiovisual Popular - Panorama 1990 - 2009. Tese de Doutorado apresentada ao Programa de Pós-Graduação em Ciências da Comunicação da Escola de Comunicações e Artes (ECA-USP). Disponível em: www.teses.usp.br/teses/disponiveis/27/27153/tde19112010113739/publico/2351228.pdf.
} 
desenvolvimento criativo encontra-se destinado apenas àqueles que podem usufruir do acesso aos movimentos do mercado que difunde o contato com a inovação e tecnologia como meios para a realização criativa [1]. Por isso, decidimos somar aos nossos objetivos, posteriormente enumerados, uma atenção especial em relação a tais discursos, afim de enfraquecê-los sempre que surgissem como uma justificativa paralisadora.

Além das oficinas, o CINUSP passou a promover também atividades que buscam realizar a interlocução entre a academia e movimentos culturais que acontecem nas periferias da cidade, como as mostras Cinema da Quebrada, realizadas em outubro de 2012 e dezembro de 2013.

Após um primeiro contato com as escolas, realizado antes da finalização do primeiro semestre de 2012, pensamos que os espaços em torno delas poderiam ser trabalhados nos filmes. Assim, a partir de algumas conversas com os alunos a respeito do que achavam sobre realizar visitas a outros locais fora do espaço escolar, à procura de locações em espaços de convívio e de encontro com outras pessoas de seus bairros, concluímos que seria interessante agregar aos nossos objetivos e metodologia atividades desenvolvidas fora das escolas, percorrendo os bairros, ainda que estes apresentem situações urbanísticas precárias e de difícil acesso.

Com esses elementos em mente, delimitamos que um de nossos objetivos, para além da realização de curta-metragens, seria o de estimular os alunos, por meio dos dispositivos audiovisuais, a explorarem novas perspectivas sobre os espaços do seu cotidiano, visando locais públicos de uso coletivo ou apenas de passagem de transeuntes. Por exemplo, além da escola, uma praça, uma rua do bairro, um centro de convivência ou qualquer outra localidade com a qual tivessem algum contato anterior. Fazendo uso dos recursos da realização audiovisual, como o plano fílmico, o recorte, a manipulação do som, a ficção e o documentário, e transformando-os em um meio catalisador de novas formas de perceber esses espaços, os alunos seriam convocados a ver e a inserir-se diferentemente no cotidiano.

Procuramos estar atentos aos novos interesses que o embate entre os alunos e seu desejo de aprender a fazer filmes pudessem gerar. Tendo isso em vista, o conceito de lugar antropológico de Marc Augé [1], definido como "simultaneamente princípio de sentido para aqueles que o habitam e princípio de inteligibilidade para quem o observa”, nos ajudaria a orientar quais práticas deveriam ser incluídas durante o andar da própria atividade.

Por fim, para concluir a elaboração das etapas do trabalho a ser desenvolvido, compreendemos que não se tratava apenas de repassar aos alunos as teorias do cinema acerca do espaço, seja ele físico, representacional, simbólico ou fílmico, como o caracterizou Jacques Aumont [2]. Temos que o espaço, no momento em que se transforma em imagem, ou em elemento fílmico, passa a ter um novo estatuto, processual e pragmático.

Com base nessas considerações conceituais, traçamos como objetivos: 1) realizar todas as etapas do processo de criação de um curta-metragem que teria exibição final no CINUSP com a presença de professores e alunos das escolas e da USP; 2 ) contribuir para que outras produções audiovisuais fossem possíveis após as atividades de nossa equipe, ou seja, que os alunos ganhassem certa autonomia no fazer; 3 ) aumentar o repertório fílmico dos alunos, diversificando o universo de formas a que eles têm 
acesso, aguçando a sua capacidade de leitura crítica de imagens; 4) provocar modos de perceber e de intervir nos espaços do cotidiano.

\section{RESULTADOS}

Alguns problemas surgiram logo após o período inicial das oficinas. Uma escola onde seria realizada uma oficina desistiu de participar, devido a falta de interesse da direção, o que nos levou a remanejar nossos objetivos para dar maior amplitude ao percurso das oficinas que se seguiriam.

Outra dificuldade que encontramos foi em relação a filmagens fora dos espaços escolares, atividades previstas em nossos objetivos. Pais de alunos mais novos, do ensino fundamental II, não autorizaram a saída de seus filhos do espaço escolar por temer a possível violência a qual estariam expostos ao transitarem pelas ruas do bairro. Enfrentamos também o desligamento de alguns dos alunos por conta da distância entre as escolas e suas casas e, sobretudo, pelo fato de parte deles ter que trabalhar, o que dificultava a permanência nas escolas após as atividades curriculares.

Ao final das oficinas, o resultado foi positivo. Cumprimos, mesmo que não de forma ideal, todos os passos do percurso até a realização dos curtas-metragens. O material produzido durante as oficinas foi exibido no CINUSP durante o evento que marcou o encerramento das atividades, contando com a participação dos alunos envolvidos, de professores, coordenadores e diretores das escolas e da equipe do CINUSP. Esse encontro gerou um interessante debate e muitos agradecimentos por parte dos alunos e da coordenação das escolas. Nesse mesmo dia, houve também uma visita monitorada à ECA. Para além desses resultados, a oficina contribuiu para a criação de um núcleo de produção audiovisual em uma das escolas. Esse núcleo produziu um vídeo que foi premiado no Festival do Minuto em 2012.

Com esses resultados positivos, passamos a vislumbrar a organização de novas oficinas para o próximo ano, levando em conta que algumas mudanças seriam necessárias.

\section{DISCUSSÃO E CONCLUSÕES}

Quando partimos para os encontros, constatamos que deveríamos esclarecer aos alunos que a nossa ação junto a eles seria pontual e que, para o desenvolvimento de um trabalho consistente, seria preciso estabelecer um acordo entre as partes. As atividades estariam relacionadas a um repertório básico de conteúdo e técnica, que demandaria continuidade em momentos "extra-oficinas" por parte deles, com apoio de professores que nos acompanhariam ao longo das atividades, tendo em vista os limites dos equipamentos que existiam na ocasião de nossa chegada e que, possivelmente, continuariam a existir após a nossa saída. Essa primeira ideia visava permitir que as escolas pudessem proporcionar alguns recursos básicos para realizações audiovisuais após o término de nossas oficinas, como o registro de eventos escolares, por exemplo.

Três principais fatores nos levaram a desenvolver reflexões, estudos e remanejamento 
de algumas de nossas estratégias e posicionamentos para futuras oficinas, o primeiro deles em relação às dificuldades que encontramos em levar os alunos a outros espaços que estivessem fora do ambiente escolar. Acabamos concluindo, em relação a isso, que deveríamos tentar ampliar nossas parcerias para além daquela realizada com a escola e que, para as próximas oficinas, seria importante nos aproximarmos de centros culturais, pontos de cultura ou ONGs presentes nas regiões próximas à escola, fortalecendo o caráter extracurricular da atividade. Assim, talvez, também conseguiríamos garantir, entre as instituições, um maior fluxo dos alunos no interior do bairro. Pensando neste novo formato, de parcerias, em poucas semanas nos aproximamos do Jardim Miriam Arte Clube ${ }^{* *}$. A escolha das escolas com as quais trabalharíamos no ano seguinte, seria, portanto, orientada pela viabilidade de um trabalho junto à instituição.

Por outro lado, em relação à desistência de alunos interessados devido, sobretudo, às dificuldades econômicas, concluímos que não tínhamos recursos suficientes para sanar este tipo de limitação. Porém, tais fatores não podiam ser ignorados e, durante a vivência com os alunos no cotidiano das escolas, admitimos ser importante uma maior reflexão sobre tais questões, à procura de um esclarecimento em relação àquilo que vigorava no interior de nossas práticas.

Para nossa compreensão a respeito dessas questões, passamos a nos pautar em estudos que discutem a situação de nosso tempo presente. Para isto, tomamos como uma de nossas referências o estudo realizado pelo filósofo francês Michel Foucault [3], que se dedicou a pensar o nascimento de um novo projeto político e econômico, supostamente consolidado no período do pós-guerra e que ficou conhecido pelo termo "neoliberalismo". Em seus escritos localizamos a exposição de debates sobre economia e governo que aconteceram nas décadas que se seguiram ao período da segunda grande guerra, quando é possível notar que o bem-estar social encontra-se cada vez menos presente em vista do surgimento de projetos sociais que têm como foco o acréscimo de capital humano, ou seja, de valor utilitário à produção do mercado. Assim, nos novos projetos a preocupação em relação à diminuição das desigualdades sociais passa a ser ofuscada em vista do aumento das possibilidades de ascensão no interior dos mecanismos da concorrência de mercado. Diante desse contexto, as oficinas atuam como instrumento capaz de criar novas formas de os alunos perceberem o mundo, ainda que a nossa intervenção frente ao cenário de desigualdade social com o qual nos deparamos não seja determinante ao ponto de possibilitar mudanças estruturais.

Diante disto, retomamos nossas reflexões, cientes de que não poderíamos nos deixar levar por questões de ordem de formação técnica com vista apenas ao mercado de trabalho. Frisamos, então, que nossos projetos futuros deviam ter como objetivo proporcionar experiências de contato com os recursos de criações audiovisuais e desmitificar os aparatos e o processo criativo e, com isso, incentivar produções independentes que intensifiquem o surgimento de novos estilos de cinema.

Por fim, outro fator que nos auxiliou a reforçar a importância de nossa função

**Fundada em 2004 pela artista plástica Mônica Nador, o JAMAC é uma associação sem fins lucrativos formada por artistas e moradores do bairro Jardim Miriam. 
primordial na formação preliminar de potenciais produtores independentes foi a descoberta de que os alunos de uma das escolas, logo após o início das primeiras oficinas, já mostravam certo domínio do processo criativo. Os alunos mais velhos expressavam noções de construção imagética, o que concorre para a desconstrução da ideia de relações pautadas por uma hierarquia entre nossos saberes. Notamos, com isso, que o que nos dava o direito de ocupar o lugar dos professores era o de "saber mais", mas não muito mais que nossos alunos. Passamos a notar que, enquanto professores, ocupávamos um lugar mais próximo ao de mestre ignorante, que abre outras possibilidades de pensamentos e criação, do que ao de sábios, portadores de algo nobre e desconhecido o qual o outro deve alcançar pelo saber - como bem caracterizou Jacques Rancière [5] a respeito de Joseph Jacotot (do professor militante do século XIX): a recusa de instruir comportamentos e explicar saberes visa valorizar, de forma igualitária, as diferentes inteligências e, assim, pode vir a desarticular algumas estratégias discursivas que fortalecem as divisões hierárquicas das inteligências.

Tais reflexões nos levaram a uma compreensão mais sincera a respeito daquilo que nós e os alunos tínhamos em comum, a saber, a vontade de realizar trabalhos de audiovisual em conjunto e, assim, obter a experiência de passar por cada uma das etapas de realização de um filme.

Por fim, confirmamos que o ensino audiovisual tem um potencial enorme de estimular o engajamento criativo de alunos. É unânime, no contato com projetos, leituras e nas nossas próprias experiências, o enorme potencial agregador e transformador do cotidiano dos alunos que a atividade audiovisual estimula. Ela abre espaço para descobertas, atiça a curiosidade em âmbitos diversos, como ciências, história, artes, etc. Os depoimentos sobre alunos interessados, que se estruturam em torno do fazer fílmico, são muitos. Os desafios de agora em diante são: manter a atividade extracurricular e desenvolver o potencial interdisciplinar. Como fazer isso na atual estrutura escolar? Outra questão suscitada é: em que medida o fazer audiovisual nas oficinas pode incrementar a formação no ensino universitário do audiovisual? Como o contato com esses alunos pode ou não mudar o fazer fílmico dos alunos e professores da universidade engajados nesse trabalho?

\section{REFERÊNCIAS}

[1] AUGÉ, M. Não Lugares: introdução a uma antropologia da super-modernidade. Campinas: Papirus, 2012.

[2] AUMONT, Jacques. O olho interminável - cinema e pintura. São Paulo: Cosac Naify, 2004.

[3] FOUCAULT, M. O Nascimento da Biopolítica. São Paulo: Martins Fontes, 2008.

[4] TOLEDO, M. Educação audiovisual popular no Brasil: panorama, 1990-2009. Tese (Doutorado em Comunicação e Artes). São Paulo: USP, 2010. $361 f .2$ v.

[5] RANCIÈRE, J. O Mestre Ignorante - cinco lições sobre a emancipação intelectual. Belo Horizonte: Autêntica, 2011. 
ANDRÉ MANFRIM graduando em Audiovisual da Escola de Comunicações e Artes da Universidade de São Paulo (ECA-USP). Diretor, fotógrafo e operador de câmera, atua como educador nas oficinas de audiovisual do projeto Novos Talentos do CINUSP Paulo Emílio

BRENO ISAAC BENEDYKT graduado em Pedagogia e mestrando da Faculdade de Educação da Universidade de São Paulo (FE-USP). Atua como educador nas oficinas de audiovisual do projeto Novos Talentos do CINUSP Paulo Emílio - e-mail: breno.benedykt@gmail.com

CHRISTIANE MATOS BATISTA graduada em Jornalismo da Universidade Federal de Sergipe e pós-graduada em Cinema, Vídeo e TV do Centro Universitário Belas Artes de São Paulo. Atua como educadora nas oficinas de audiovisual do projeto Novos Talentos do CINUSP Paulo Emílio.

MARCos yoshi graduado em Audiovisual da Escola de Comunicações e Artes da Universidade de São Paulo (ECA-USP). Diretor, fotógrafo e operador de câmera, atua como educador nas oficinas de audiovisual do projeto Novos Talentos do CINUSP Paulo Emílio

THIAgO BATISTA BEZERRA graduando em Pedagogia da Faculdade de Educação da Universidade de São Paulo (FE-USP). Atua como educador nas oficinas de audiovisual do projeto Novos Talentos do CINUSP Paulo Emílio 